\title{
DUMPING SOCIAL
}

\section{TRANSNACIONAL E A \\ REPÚBLICA POPULAR DA CHINA}

TRANSNATIONAL SOCIAL DUMPING AND

THE PEOPLE'S REPUBLIC OF CHINA

RESUMO: O presente trabalho cuida de analisar as condições de trabalho no território chinês e sua origem para a concretização de uma conduta anticoncorrencial construída pela doutrina especializada e denominada dumping social. A pesquisa centra-se fundamentalmente numa análise de caso, razão pela qual utiliza o método empírico para desenvolver suas propostas e se socorre de dados técnicos e revisão bibliográfica acerca do tema. Conclui que o empoderamento dos sindicatos e dos trabalhadores chineses, bem como o acesso à informação das circunstâncias de contratação e gestão da mão de obra são instrumentos úteis para minimizar os efeitos econômicos do rebaixamento de salários e demais condições trabalhistas.

Palavras-chave: Dumping Social. China. Trabalho.
ABSTRACT: The current paper analyzes the working conditions in China and its origin to the implementation of an anti-competitive conduct built by specialized doctrine and called social dumping. The research focuses primarily on a case-analysis and for that reason uses the empirical method to develop their proposals and applies a technical data and literature review on the subject. It concludes that the empowerment of trade unions and Chinese workers, as well as access to information of hiring conditions and labor management are useful instruments to mitigate the economic effects of the lowering of wages and other working conditions.

Keywords: Social dumping. China. Labor.

\footnotetext{
${ }^{1}$ Professor de Direito do Trabalho do Centro Universitário do Rio Grande do Norte (UNI-RN). Doutor em Direitos Humanos e Desenvolvimento pela Universidade Federal da Paraíba (UFPB). Oficial de Justiça Avaliador Federal do Tribunal Regional do Trabalho da 21ạ Região.
} 


\section{INTRODUÇÃO}

A China tem se destacado como um centro de produção e potência global. Com taxas de crescimento anuais do Produto Interno Bruto que superam as mais otimistas para um mundo que oscila entre crise e superávit, a China ganhou um espaço próprio no cenário internacional ${ }^{2}$. A abertura comercial ao capitalismo global, desde o final da década de 1970, permitiu a este país, de tradição secular comunista, a experiência de um ator global com várias particularidades, que sinalizam um tipo híbrido de capitalismo de Estado com permissão à iniciativa privada para a exploração da atividade empresarial que convive com irrisória liberdade individual ${ }^{3}$. Além da produção têxtil, de calçados e eletrônicos, o território chinês tem servido, por razões geográficas, jurídicas, regulatórias e fiscalizatórias, como um paraíso para grandes corporações do setor tecnológico. A explosão de crescimento econômico chinês evidencia-se ao mesmo tempo em que há uma prioridade por investimentos em cidades e zonas costeiras (que facilitam o escoamento da produção), um descontrolado processo migratório interno de trabalhadores e denúncias de lesões ambientais nos processos produtivos.

O Ministério do Desenvolvimento, Indústria e Comércio Exterior (MDIC), vinculado à Presidência da República, mantém na sua estrutura administrativa a Secretaria de Comércio Exterior (SECEX), que reúne quatro departamentos: o Departamento de Operações de Comércio Exterior (DECEX), o Departamento de Negociações Internacionais (DEINT), o Departamento de Defesa Comercial (DECOM), o Departamento de Estatística e

\footnotetext{
${ }^{2}$ Um relatório do World Bank, de 2011 informa, demonstra que entre 1990 e 2009, o Produto Interno Bruto Chinês cresceu 560,22\%, maior índice registrado dentre todos os países, rendendo-lhe a terceira posição no ranking das maiores economias do mundo. Entre 2006 e 2014, saiu de um PIB de US\$ 2.729.784.031.906,1 para US\$ 10.360.105.247.908 em 2014. Cf. WORLD BANK. World Development Indicators. Washington D.C.: Disponível em: < http://data.worldbank.org/country/china\#cp gep>. Acesso em: 05 out. 2015.

${ }^{3}$ Segundo o estudo 2015 Index of Economic Freedom - Promoting Economic Opportunity and Prosperity, publicado pela The Heritage Foundation, a China é o 139 país (dentre 178 mapeados) em liberdade econômica, com pontuação 52.7, considerado majoritariamente não livre, de acordo com os parâmetros do levantamento, que considera os seguintes itens: liberdade de empreendimento, liberdade de negociação, liberdade fiscal, gastos governamentais, liberdade monetária, liberdade de investimento, liberdade financeira, direitos de propriedade, índice de corrupção e liberdade de trabalho. Disponível em: <http://www.heritage.org/index/pdf/2015/book/Highlights.pdf>. Acesso em: 05 out. 2015.
} 
Apoio à Exportação (DEAEX) e o Departamento de Competitividade no Comércio Exterior (DECOE).

O DECOM possui atribuição delineada pelo art. 29 da Portaria GM/MDIC № 06, de 11 de janeiro de 2008. Após a apuração de condutas que configurem práticas desleais no âmbito do comércio transnacional reconhecidas pela Organização Mundial do Comércio, o DECOM emite parecer que, ao final, será apreciado pela Câmara de Comércio ExteriorCAMEX, órgão integrante do Conselho de Governo da Presidência da República e tem por objetivo a formulação, adoção, implementação e coordenação de políticas e atividades relativas ao comércio exterior de bens e serviços, incluindo o turismo ${ }^{4}$.

Havendo contestação sobre preços praticados por agentes em regime de concorrência estrangeiros, a CAMEX decide pela fixação de direitos antidumping e compensatórios, provisórios ou definitivos, e salvaguardas, nos termos do art. 2ํㅡ, inciso $X V$, do Decreto № 4.732, de 10 de junho de 2003. Ocorre que as investigações para a configuração de dumping exigem a participação, no processo administrativo, de todas as partes interessadas, e em determinados casos não há a cooperação das empresas acusadas da conduta desleal e dos países exportadores.

Este trabalho teve por objetivo analisar a ocorrência do dumping social transnacional desde as condições de trabalho chinesas e da respectiva legislação trabalhista.

\section{A REPÚBLICA POPULAR DA CHINA: CONTEXTUALIZAÇÃO ECONÔMICA E TRABALHISTA}

Os produtos chineses têm ganhado destaque frente à DECOM em face das queixas apresentadas por alguns setores da indústria nacional brasileira que alegam prejuízo grave ou ameaça de prejuízo grave decorrente da entrada de produtos chineses em sistema de competição desleal com os brasileiros. Para a configuração de dano à indústria nacional, o MDIC avalia a evolução dos indicadores das importações e da indústria doméstica. Para aferir a ameaça considera, além dos fatores acima, avalia-se a

\footnotetext{
${ }^{4}$ A CAMEX É composta pelo Ministro de Estado do Desenvolvimento, Indústria e Comércio Exterior, a quem cabe a presidência da CAMEX, e pelos Ministros de Estado Chefe da Casa Civil; das Relações Exteriores; da Fazenda; da Agricultura, Pecuária e Abastecimento; do Planejamento, Orçamento e Gestão; e do Desenvolvimento Agrário.
} 
taxa de crescimento significativa das importações do produto objeto de dumping; a suficiente capacidade ociosa ou iminente aumento substancial na capacidade produtiva do produtor estrangeiro; as importações realizadas a preços que terão efeito significativo em reduzir preços domésticos ou impedir o aumento dos mesmos; e estoques do produto sob investigação.

Alegam os produtores brasileiros que as empresas chinesas se utilizam da prática de preços de exportação inferior àquele que pratica para o produto similar nas vendas para o seu mercado interno. Existem 155 procedimentos originais ou revisionais de aplicação de direito antidumping em vigor, sendo 62 deles referentes à China, os quais dizem respeito a diversos produtos oriundos deste país: calçados, chapas acrílicas, chapas grossas, chapas off-set, eletrodos de grafite, filmes de PET, imãs de ferrite, lápis de madeira, magnésio metálico, pneus de carga, porcelanato técnico, seringas descartáveis, tubos de cobre ranhurados, tubos de plástico para coleta de sangue a vácuo, vidros planos flotados incolores e ácido adípico (MDC, 2015).

Diante da repressão brasileira aos produtos chineses que causaram danos à indústria doméstica, a estratégia de alguns importadores, a exemplo do setor de calçados, foi de realizar triangulação, diminuindo a importação direta da China e aumentando a de países como Vietnã, Malásia, Indonésia e Hong Kong, que funcionavam como meros certificadores dos produtos e não estavam sujeitos às taxas antidumping aplicados diretamente aos produtos chineses.

Numa das investigações, iniciada em dezembro de 2008, a pedido da Associação Brasileira das Indústrias de Calçados (Abicalçados), na qual foi aplicado o direito antidumping definitivo até 05 de março de 2015, constatou-se que a prática desleal resultara em queda de preços, redução das vendas de produtos internos e diminuição de empregos no setor, originados pela conduta predatória chinesa, que se utiliza, dentre outros artifícios, de uma gestão de trabalho questionável, contrariando a doutrina do

(...) fair trade, também conhecida como comércio justo, segundo a qual o mercado internacional não deve consumir produtos de países que descumprem a legislação trabalhista e explorem seus trabalhadores. Para os adeptos dessa corrente, numa situação como essa, nasce, para os demais países, uma obrigação moral e ética de não tirar proveito de quem é explorado (SILVA, 2012, p.47). 
A guerra pela atração de investimentos no cenário global e transnacional, necessariamente, passa pelo incentivo fiscal e de condições comerciais. A corrida pela eficiência ignora a observância de questões relativas aos direitos humanos, tornando indiferente a muitos produtores se a prática empresarial que exercem é proba ou não, restando como prioridade a obtenção de um volume de mercado cada vez maior.

As resoluções da CAMEX consideram exclusivamente os critérios constantes nos acordos internacionais em matéria comercial para a configuração do dumping, isto é, os custos unitários do produto similar que serve como paradigma - como são os custos de produção (excluídos os trabalhistas na análise da DECOM por falta de previsão no âmbito internacional), os administrativos e os custos de produção. Isto significa que custos produtivos que levam em conta a força de trabalho nas fábricas chinesas não são objeto de investigações pelo MDIC, até mesmo pela inviabilidade técnica e jurídica sancionatória, que acabaria por adentrar em questões de soberania legislativa daquele país e comprovação de ausência de aplicabilidade da legislação de fiscalização por parte dos órgãos competentes em solo chinês. Além disso, registre-se a lacuna de responsabilização internacional do Estado por violação de direitos trabalhistas e inexistência de cooperação internacional fiscal para o combate de tais condutas e os reflexos de ordem diplomática e econômica decorrentes de sanções econômicas, ampliação das aplicações de direito antidumping contra parceiros comerciais de grande envergadura econômica, tais como a China.

A República Popular da China é acusada, por muitos produtores globais, de tolerar violações de direitos humanos no processo de crescimento econômico. O capitalismo chinês, entretanto, tem servido como mecanismo de promoção social de pessoas de um mundo de miséria para um patamar superior de acesso a bens e serviços. Os índices sociais de desenvolvimento humano da China melhoraram substancialmente após o período o boom econômico proporcionado pelas políticas de industrialização nos últimos vinte e cinco anos, com registros acima da média mundial:

(...) enquanto o mundo melhorou seu índice em $9 \%$ de 2000 a 2010, saltando de 0,570 para 0,624, a China registrou variação de 17\%, atingindo 0,663 em 2010 
(...) Comparado ao Brasil, o crescimento chinês foi praticamente o dobro do período (MASIERO et al., 2012, p. 67).

A explicação não exige maiores aprofundamentos: por menor que seja o aumento de liberdade econômica, a qualidade geral de uma população é elevada e o governo chinês preferiu a via do progresso econômico que repercute diretamente na qualidade de vida dos seus nacionais.

Com uma população de aproximadamente 1,364 bilhões de pessoas, a China significa um grande mercado consumidor, uma proximidade a fornecedores de matériasprimas por países asiáticos para a indústria dos eletrônicos e uma farta mão de obra com baixo poder de negociação salarial, embora a faixa de remuneração mínima oficial seja próxima à brasileira, de difícil fiscalização pelas autoridades governamentais. O modelo chinês pauta-se numa superprodução industrial exportadora que requer larga oferta de mão de obra, originária primariamente das estatais e de um êxodo rural famélico que não cessa e fornece um exército disponível por baixo salários oferecidos por filiais, parceiras e terceirizadas de grandes companhias ou que com elas celebram contratos de facção.

No início dos anos 90, o Conselho de Estado Chinês, por meio do plano decenal (1991-2000), priorizou uma política industrial desenvolvimentista de atração de investimentos diretos estrangeiros, combinada com uma intervenção estatal na economia que promovesse os setores de alta tecnologia, tais como eletrônicos, máquinas e bens manufaturados, indústria de base, setores metal-mecânico de bens de capital e de produtos químicos. A estratégia chinesa de desenvolvimento setorizado deu resultados ascendentes. Influenciada pela experiência dos vizinhos asiáticos e com uma política agressiva de industrialização e internacionalização (produzindo por meio dos créditos e investimentos diretos estrangeiros e com as exportações e importações - comércio exterior), a execução do oitavo plano quinquenal (1991-1995) e do nono plano quinquenal (1996-2001) investiu no que a regra básica do desenvolvimento econômico leciona: diminuir as exportações de bens primários e incrementar o parque industrial para deixar de ser um país agrícola para passar ao seleto grupo dos industrializados (MASIERO et al, 2012, p. 53-55). 
Em razão deste cenário e da participação cada vez maior na matriz comercial internacional (em 2001, a China foi oficialmente admitida como membro da Organização Mundial do Comércio), a legislação trabalhista chinesa recebeu olhares mais atentos, pois sua alteração, assim como a adoção dos patamares salariais, influencia diretamente na escolha de investidores transnacionais sobre a instalação das unidades produtivas.

As mudanças no sistema regulatório trabalhista chinês estão visceralmente conectadas ao redesenho jurídico de suporte ao desenvolvimento e à transição de uma economia socialista para uma de abertura de mercado. Estima-se que a força de trabalho chinesa consista em mais de 800 milhões de trabalhadores, sendo pelo menos 130 milhões de migrantes oriundos do campesinato, que remetem parte dos salários pagos para sustentar ou ajudar na manutenção das famílias nas localidades de onde saíram (JACKSON, 2011, p. 2).

O perfil laboral chinês, com isso, figura-se como de baixa qualificação, constituindo uma força basicamente manual, que não atende aos reclames de postos que exigem maior qualificação, e põe, em termos salariais, no mesmo nível graduados universitários e operários industriais, ainda que a ascensão na carreira seja mais rápida e vantajosa para os primeiros.

A mudança das leis trabalhistas chinesas se deu sensivelmente desde o momento de saída de um modelo que concentrava escritórios governamentais, os quais alocavam os trabalhadores para os empregadores disponíveis (JACKSON, 2011, p. 2-3). Os empregados detinham estabilidade no emprego e manutenção de benefícios sociais, só podendo ser dispensados por faltas graves. No início da década de 1980, pequenas reformas trabalhistas foram realizadas, quando foram instituídos juridicamente os contratos por prazo determinado e, em 1992, foi promulgada uma lei sindical que submetia todos os entes coletivos trabalhistas do país ao All-China Federation do Trade Unions-ACFTU, sob o comando do governo central, numa espécie de unicidade sindical estatal que, conquanto nos últimos anos, tenha militado mais ostensivamente pelos direitos trabalhistas ainda criminaliza qualquer tentativa de criação de sindicatos livres, autônomos e não filiados à ACFTU. 
Os sindicatos chineses têm uma percepção diferente da noção coletiva de outros locais. Verifica-se a existência de sindicatos de trabalhadores capturados e custeados pelos empregadores, grande repressão às lideranças sindicais que monopolizam as negociações e comprometem movimentos reivindicatórios de melhores salários e condições de vida.

O papel dos sindicatos chineses é dar suporte local aos trabalhadores e de contenção das agitações dos trabalhadores. Eles funcionam como bases do partido comunista chinês na intermediação com as empresas sem que isto signifique um conflito coletivo de trabalho e interferências nos interesses desenvolvimentistas do país. As dificuldades de negociação quanto aos salários e cláusulas de trabalho eclodiram uma onda de greves em 2010, que se iniciaram numa fábrica da Honda Autoparts Manufacturing, em Foshan (província de Guangdong) capitaneadas por estagiários e trabalhadores temporários que recebiam em torno de US\$ 144 de salário mensal, seguindo-se pela greve dos trabalhadores da Honda Lock, em Zhongshan, da Hyundai e Toyota, em Pequim e Tianjin respectivamente e dos trabalhadores da Foxconn e resultaram em pelo menos treze greves nas cadeias produtivas japonesas na China e que atingiram o setor alimentício e têxtil (MASIERO et al, 2012, p.185-194).

Ainda que a organização autônoma e a deflagração do respectivo movimento paredista sejam proibidas na China, as greves de 2010 foram toleradas e permitidas pelo governo (com algumas repressões ao movimento) e serviram de vitrine das precárias condições salariais e de trabalho incrustradas em setores industriais para a imprensa e comunidade internacional. A visibilidade conferida ao obscuro mundo do trabalho chinês foi precisamente descrita pela sequência de catorze suicídios de trabalhadores da Foxconn, vítimas de uma rotina de trabalhos mais assemelhada a um campo de concentração do que a uma relação empregatícia. Os fatos exigiram das autoridades chinesas maior firmeza na efetividade das regras que edita, aumento do valor do salário mínimo e alteração na política trabalhista, além de compelir as grandes corporações a 
reverem os padrões de trabalho e de salários pagos aos operários, resultando num aumento entre $24 \%$ e $34 \%{ }^{5}$.

Em 1994, um conjunto de reformas econômicas e trabalhistas tomou parte do cenário chinês, com o fechamento de empresas estatais, eliminação de mais de quarenta milhões de postos de trabalho, alteração da pobre província de Guandong para um importante centro industrial a partir de investimentos da iniciativa privada nacional e de Hong Kong. Em 01 de julho de 1995, entrou em vigor a Lei do Trabalho da República Popular da China com aplicabilidade às empresas privadas e estatais e que convivem com regulamentos laborais próprios das províncias, das maiores cidades e de algumas zonas econômicas especiais. A lei do contrato de trabalho, com vigor a partir de 01 de janeiro de 2008, concedeu maior liberdade de negociação entre empregados e empregadores, criou um rol de direitos individuais e fortaleceu a representação coletiva, impôs contratos escritos com cláusulas explícitas sobre a descrição do emprego, períodos de descanso, salário, condições de trabalho e maiores proteções trabalhistas para os que forem contratados com a intermediação de agências de emprego (BAKER \& MCKENZIE INTERNATIONAL, 2013, p. 4-5).

O diferencial da economia chinesa nos custos trabalhistas de produção se dá pelas várias opções de níveis remuneratórios, pela frágil vigilância com acidentes e doenças do trabalho oriundos das jornadas extenuantes de atividades repetitivas e falta de treinamento adequado aos trabalhadores. O salário mínimo é fixado - por hora ou por mês - pelas províncias e municípios, cuja variação do salário médio pago pode se dá em até três vezes de uma região para outra e com patamares consideravelmente inferiores aos salários pagos nos países desenvolvidos.

A lei geral do contrato de trabalho chinesa, com 27 artigos, estabelece um módulo de jornada semanal de quarenta horas, durante cinco dias, prevê a remuneração extraordinária (entre 150 e 300\% de adicional sobre a hora normal) pelo excesso de

\footnotetext{
${ }^{5}$ Ainda assim há questionamentos acerca dessas porcentagens, pois o salário nas fábricas da Foxconn, por exemplo, calcula-se por salário-base ao que se somam as horas extras, gratificação por desempenho e bônus. 0 reajuste concedido se deu sobre o valor básico (de US\$ 172 para US\$ 190), só configurando um aumento real se os trabalhadores continuassem a prestar horas extraordinárias e se adequassem ao ritmo de produção exploratória da empresa. Somente após as contínuas denúncias dos trabalhadores e da cobrança dos clientes da Foxconn, a empresa concedeu reajuste sobre o vencimento básico.
} 
jornada de trabalho, limitando-se a um quantitativo de um a três horas por dia e trinta e seis horas por mês. A grande massa de trabalhadores pobres e desqualificados contemplada com baixos salários cria um cenário de opção pelas jornadas exaustivas, que se anacroniza nos casos de salário pago por peça ou tarefa e face aos descontos ilegais realizados por defeitos e atrasos na produção (JACKSON, 2011, p. 5-6).

Os monitoramentos feitos em várias cidades das distintas regiões chinesas registraram atrasos nos pagamentos dos salários e não pagamento das horas extraordinárias, salários pagos abaixo do mínimo permitido, a prática de discriminação com os trabalhadores migrantes, alto índice de informalidade dos contratos de trabalho e jornadas de trabalho de até oitenta horas semanais (MASIERO et al, 2012, p. 175-177).

O questionamento em relação aos níveis e qualidade dos postos de trabalho nos Estados Centrais suscita a erosão dos níveis de pagamento e empregabilidade desses países em razão da corrida pela eficiência em solo chinês. O que se considera aqui não é a relação entre o salário e custo de vida, dado que não se podem comparar objetivamente condições de vida distintas, mas a vantagem comparativa obtida pelas corporações ao se utilizarem de baixas remunerações e não investirem em segurança e saúde no trabalho ou incidirem em trabalho infantil, gerando lucro incorporado, comparado aos que teriam em seus Estados de origem, obstaculizando a fiscalização das regras trabalhistas.

A legislação chinesa contempla regras de proteção previdenciária, de direito ambiental do trabalho. Contém obrigações de informação e proteção à integridade física dos empregados sendo umas compulsórias quanto ao fornecimento de treinamento e equipamentos de proteção, outras mandamentais quanto à possibilidade de recusa ao cumprimento de ordens que representem risco à saúde e segurança do trabalhador. Há a exigência de aviso prévio de trinta dias para o rompimento do contrato laboral e a proibição do trabalho infantil para menores de dezesseis anos. Dispositivos legais na legislação chinesa preveem a promoção de isonomia entre homens e mulheres, inserção de pessoas com deficiência no mercado de trabalho, vedação de contratação discriminatória e absorção da força de trabalho de nacionalidades minoritárias, segurodesemprego, indenização por acidentes de trabalho e doenças profissionais e 
ocupacionais e uma rede de seguridade social nacional similar à brasileira, inclusive como previsão de aposentadorias e benefícios previdenciários.

Atribui-se a diminuta eficácia social da legislação chinesa à indiferença de muitos empregadores, às sanções administrativas inconsistentes no âmbito local, ao desconhecimento dos direitos trabalhistas pelos trabalhadores dado o baixo nível de instrução e ao medo de represálias dos empregadores em casos de denúncias de descumprimento da legislação, além de outros fatores que tem despertado a preocupação do Partido Comunista Chinês e em larga escala servem a um sistema de lento progresso da legislação e aplicação do direito positivo daquele país (BAKER \& MCKENZIE INTERNATIONAL, 2013, p. 1-2).

A atuação solitária da lei, por si só, nunca dirimiu os problemas da humanidade, porquanto não possui vida própria e autoaplicabilidade. Até a mais alta expressão de um Direito Estatal - a Constituição -, nas palavras de Ferdinand Lassale, nada mais é do que folha de papel se comparada às forças reais de poder. Nessa toada, tal qual como ocorre com matérias referentes à Propriedade Intelectual e de Direito Ambiental, devidamente disciplinadas normativamente, não se destinam recursos suficientes para agências e órgãos com protocolos de cooperação para aplicação e cumprimento das leis trabalhistas existentes (ZIMMERMAN, 2007, p. 3).

A atividade de fiscalização administrativa da legislação trabalhista é realizada parcialmente (é necessária a previsão contratual) pelos sindicatos, mas, eminentemente, por agentes do Estado, no âmbito do Ministério dos Recursos Humanos e da Seguridade Social e dos departamentos administrativos locais com todas as prerrogativas de poder de polícia, podendo ter acesso e inspecionar locais de trabalho, documentos e equipamentos de segurança fornecidos pelos empregadores (ZIMMERMAN, 2007, p.4). Se noticiada uma violação de direitos trabalhistas, as punições variam (de acordo com a natureza do direito) entre multas, suspensão e cassação da licença de funcionamento da empresa, com possíveis repercussões criminais indiciadas pela secretaria de segurança pública chinesa, no caso de serem verificadas violações de bens jurídicos tutelados pelo direito penal do trabalho, a exemplo de cárcere privado e violência no ambiente de trabalho. 
A despeito de existir uma tutela normativa, a distribuição dos deveres dela decorrente é duvidosa. O ônus de reportar acidentes de trabalho, por exemplo, recai especialmente sobre os trabalhadores, os quais devem comprovar que há vínculo contratual com seus empregadores para fazer jus aos benefícios previdenciários.

Durante o período de recuperação e do tratamento médico, o ônus de pagamento salarial é do empregador. Se o acidente de trabalho foi causado por culpa exclusiva da vítima, o benefício é negado, mesmo que o sinistro laboral tenha se dado em razão da fadiga, distração e falta de treinamento. Caso consigam obter o auxilio governamental, os trabalhadores podem esperar anos ou meses diante da burocracia estatal e da diversidade de regras existentes. Contudo, desde 2011, com a nova regulamentação dos seguros relativos aos danos decorrentes do trabalho, o governo chinês tem tentado reduzir os prazos para a concessão dos auxílios securitários (JACKSON, 2011, p. 8-9).

\section{CASO APPLE}

O mercado chinês está repleto de multinacionais europeias, norte-americanas e asiáticas. O país depara-se com um mosaico econômico que associa práticas institucionais de variadas culturas, com formas absolutamente distintas de enxergar o mundo do trabalho. Existem quatro perfis de empresas na ordem econômica sínica: as estatais; as companhias privadas domésticas; empresas estrangeiras; as híbridas, que atuam em sistema de joint-ventures. O direito trabalhista chinês é aplicável a todos os empregados que prestem o serviço no âmbito nacional, independentemente da origem e do tipo de companhia a qual estejam subordinados.

Não obstante a dogmática jurídica assegure um conjunto de direitos fundamentais trabalhistas e existam instrumentos de combate às ilegalidades, alguns casos noticiados chamaram atenção e redirecionaram o foco para empresas transnacionais, que fornecem produtos integrantes do cotidiano da modernidade. O simbolismo das marcas de tecnologia, vestuários, calçados e automóveis se alimenta de uma necessidade de consumo e expansão de lucratividade que se socorre de novas formas de produção e segmentação que põem em cena a abertura chinesa a essas empresas antes impedidas de atuação pelo modelo comunista estatizante. 
Uma das marcas com funcionamento, no território chinês, é a Apple. Afora os casos de contrafação e pirataria dos produtos da marca fundada por Steve Jobs, a China é considerada um país parceiro na montagem de aparelhos eletrônicos e no fornecimento de peças dentro do processo de desterritorialização produtiva da Apple. Atualmente, basicamente o continente asiático mantém toda a coluna produtiva da empresa.

Conhecida por ter um modo particular de trabalhar e revolucionar a indústria da tecnologia, a Apple historicamente adotou a política do sigilo interno e externo quanto a suas operações, indo na contramão das teorias de governança corporativa que pregam uma transparência (LASHINSKY, 2012, p. 25). As queixas ventiladas na mídia sobre suas parceiras e métodos de gestão do mundo de trabalho forçaram a companhia a rever seu modus operandi.

Detentora dos direitos de propriedade intelectual e fabricante dos conhecidos produtos da linha I (Ipad, Iphone, Ipod, Itunes), sediada em Cupertino, no Vale do Silício, a Apple Computer Incorporation foi fundada em 1975 por Steve Jobs e Steve Wozniak. No início dos anos 1990, enquanto o mercado de computadores crescia exponencialmente nos Estados Unidos, a estratégia utilizada para conferir competitividade à Apple focou-se em duas frentes:

(...) investimentos em pesquisa e desenvolvimento para viabilizar o fornecimento de uma variedade de novos produtos e redução de custos para manter ou melhorar as margens de lucratividade enquanto reduzia os preços" (KOPCZAK, 1998, p.188).

A segunda opção se iniciou por um deslocamento dos centros de distribuição e operação de serviços da área costeira de São Francisco para Sacramento, na Califórnia. A fase de internacionalização dor fornecedores e subsidiárias montadoras foi inaugurada pela instalação de um ponto central de fornecimento, em Cork, Irlanda, em 1991. Com os subsídios fiscais, a proximidade aos mercados consumidores e da matéria-prima passou por uma internacionalização dos seus ativos e expandiu a malha produtiva e de consumo, nos últimos vinte e cinco anos, para os demais continentes.

A concepção e o desenvolvimento dos produtos são feitos nos Estados Unidos, o fornecimento das partes componentes é realizado difusamente por empresas nos 
Estados Unidos, China, Ásia e Europa, a fabricação na China, a armazenagem nos Estados Unidos e a distribuição feita desde cada continente. Em território chinês, grande parte da fabricação se concentra na cidade de Shenzen, local onde a montagem dos Ipads e Iphones é realizada primariamente pela fornecedora Foxconn, que tem na Hon Hai Precision Industry Corporation Foxconn, fundada por Terry Gou e sediada em Taiwan, sua empresa matriz. Trata-se de uma espécie de terceirização, tratada como empresa parceira nos relatórios de responsabilidade socioambiental da Apple.

Possuidora de mais de vinte fábricas na China, a maior parte delas concentra-se em Shenzen (província de Guandong) e Chengdu, a Foxconn mantém um verdadeiro campo de produção em larga escala com aproximadamente quinhentos mil empregados. A Foxconn ganhou notoriedade pelas greves deflagradas e denúncias veiculadas, desde 2010, acerca das condições de trabalho nas suas fábricas que culminaram com o suicídio de catorze empregados.

A Foxconn é fornecedora de outras grandes empresas como Hewlett-Packard, Dell, Motorola, Nintendo, Nokia e Sony e sua notoriedade se deve, principalmente, pelo regime de trabalho que impõe aos seus empregados e pela utilização de métodos rígidos de manutenção de rotinas trabalhistas. Após as mortes de 2010, acadêmicos chineses, de Hong Kong e de Taiwan, elaboraram relatórios e pesquisas sobre as condições de trabalho na Foxconn, que constataram a prática de jornadas excessivas e contratação de trabalhadores infantis, diminuta concessão de dias de descanso, além da elevada cobrança produtiva:

[...] o número de folgas para $75 \%$ dos trabalhadores da Foxconn é 4 , enquanto $8 \%$ do total de empregados têm menos de 4 dias mensais de descanso (Três locais - Grupo de Pesquisa de Universidades sobre a Foxconn, 2010). Cerca de $73 \%$ dos trabalhadores têm jornada superior a 10 horas, e em média os trabalhadores acumulam 83 horas extras de trabalho por mês, violando a lei chinesa que fixa um máximo de 36 horas extras por mês.

As metas de produção fixadas pela Foxconn são muito difíceis de atingir, ainda que com 10 horas/dia de trabalho. A empresa exige que os trabalhadores se "voluntariem" a fazer horas extras que não são remuneradas e, muitas vezes, são necessárias até duas por dia para atingir as metas. O departamento responsável pela administração da 
produção calcula com precisão de segundos o tempo que cada funcionário leva para cada procedimento, para organizar a produção de forma mais eficiente. (MASIERO et al., 2012, p.191-192)

A Foxconn funciona durante vinte e quatro horas por dia. Utiliza-se, como quase todas as grandes indústrias chinesas, um sistema de dormitórios conhecido como danwei, com aproximadamente 10 pessoas por quartos, que estabiliza o fluxo migratório de trabalhadores para as cidades e permite um maior controle da vida privada dos trabalhadores, conformando toda a vida do sujeito à rotina do trabalho. Considerando que os horários de circulação, de entrada e saída (além da proibição de visitas) são previamente fixados, qualquer convocação para serviços extraordinários torna-se facilitada, dada a proximidade ao local de trabalho.

Diante das denúncias e pressões para o aperfeiçoamento das condições de trabalho, os executivos da Foxconn optaram por aumentar o salário mínimo de US\$152 para US\$ 320, limitaram os dormitórios a abrigarem agora 8 trabalhadores por quarto e restringiram a jornada de trabalho semanal ao máximo de sessenta horas. Frente ao aumento e ao encarecimento dos patamares salariais e à repercussão no preço dos produtos, a Apple passou a adquirir parte dos seus produtos de outra empresa, a Pegatron Corporation. Esta, de origem taiwanesa, com fábricas na China, cujos custos trabalhistas são oito por cento menor que os da Foxconn, submete seus trabalhadores a até 100 horas extraordinárias por mês, gerando uma economia competitiva de sessenta e um milhões de dólares por ano em apenas uma das fábricas (Shanghai) se comparada à planta industrial da Foxconn em Longhua (GOLD, 2012).

A Pegatron não tem recebido a mesma atenção dispensada à Foxconn, motivo pelo qual não implantou melhorias nas condições de trabalho e obtém vantagens competitivas frente a sua concorrente. A resposta da Foxconn às quedas de receitas tem sido a interiorização de fábricas na China e os deslocamentos para Índia, por exemplo, onde os salários são mais baixos e os custos trabalhistas menores.

A corrida pela eficiência de custos tem beneficiado diretamente a Apple. Responsável por três quintos da lucratividade da indústria de dispositivos móveis, a companhia tem um grande poder de exigir auditorias e fiscalizar melhores condições de 
trabalho na sua cadeia produtiva de forma que isto signifique uma melhoria substantiva na vida dos milhares de trabalhadores envolvidos na cadeia produtiva. Quanto à lucratividade da Apple, note-se que o dumping social transnacional não se dá pela diminuição do valor dos seus produtos, mas pela incorporação da economia com baixos custos laborais na sua lucratividade, sem desconsiderar outros fatores que sejam, de fato, um mérito da empresa.

Segundo estudos e monitoramentos realizados pela China Labor Watch, no universo estimado de 1.5 milhões de trabalhadores envolvidos na cadeia produtiva da Apple - com jornada média de 55 horas semanais, durante 13 semanas num trimestre e com um custo trabalhista de US\$ 3.16 dólares por trabalhador - os custos trabalhistas foram de 3.4 bilhões de dólares, que correspondem a $18 \%$ do lucro líquido e $4.4 \%$ do total de receitas (CHINA LABOR WATCH, 2015, p. 3).

A mudança de fornecedor da Foxconn para a Pegatron pela Apple implicou, logo em 2010, uma virada nas taxas de crescimento e lucratividade destas duas empresas. A disputa pelos grandes clientes pôs em pauta a influência da melhoria das condições de trabalho sobre as receitas das companhias. Dado que os custos aumentaram para a Foxconn, isso encareceu os produtos negociados, repercutindo nas vendas, nas taxas de crescimento anuais compostas e no valor das ações no mercado de valores (Gráfico 1) (CHINA LABOR WATCH, 2015, p. 4): 


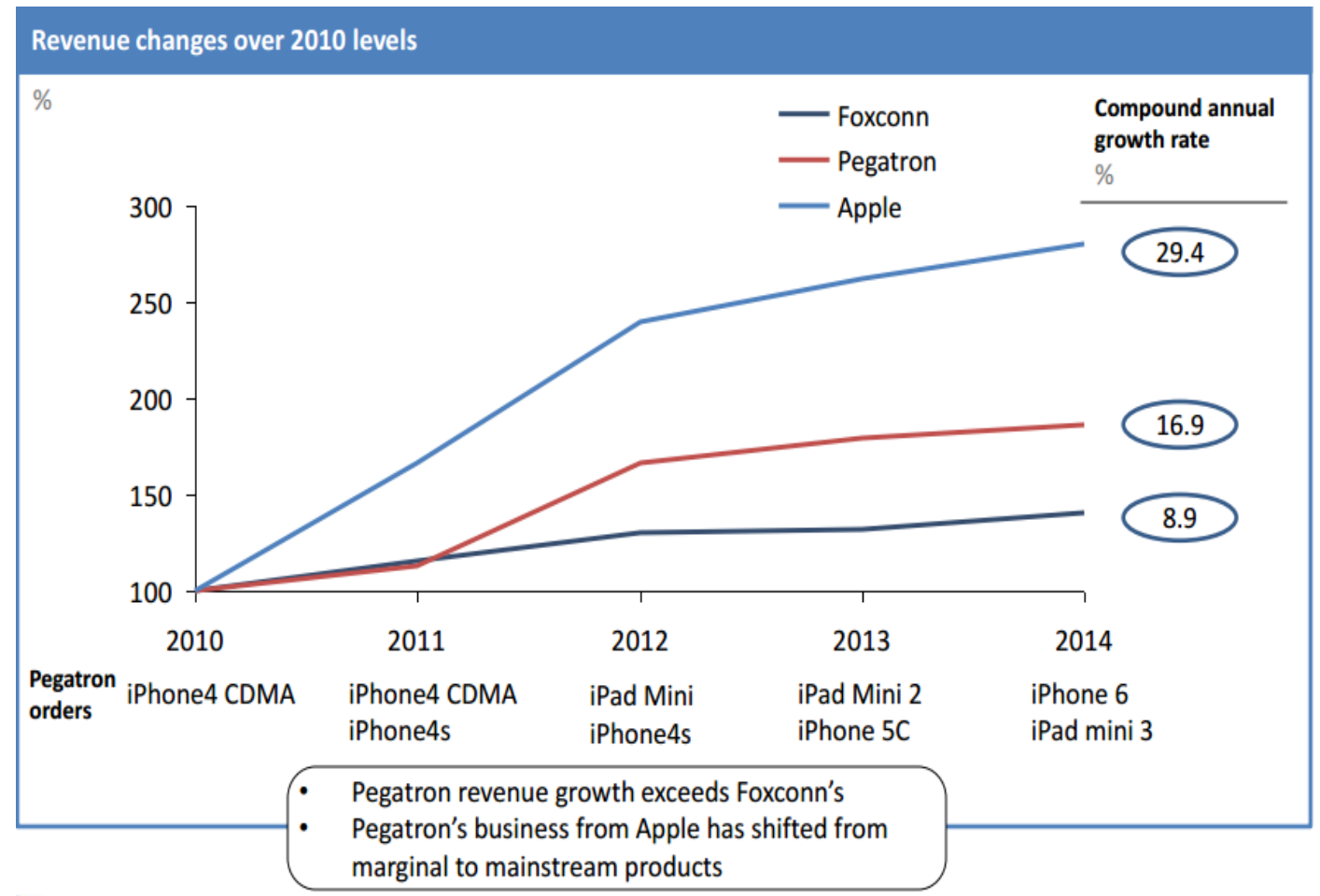

Gráfico 1 - Variações de receitas em relação aos níveis de 2010

A Pegatron, por não incorporar maiores custos laborais oriundos das greves de 2010, tornou-se uma opção mais vantajosa para a Apple, que cresceu proporcionalmente mais do que a soma da taxa das duas fornecedoras em conjunto. Um registro deve ser anotado: a cadeia produtiva pulverizada da Apple não se resume ao custo produtivo. Ela considera as menores tributações sobre os rendimentos em territórios estrangeiros, a escalabilidade e o abastecimento de risco de toda a cadeia, isto é, a flexibilidade de troca de fornecedores e capacidade de arregimentação de trabalhadores e disponibilidade destes para produções e trabalhos de alterações de emergência num prazo curto que atenda às demandas de mercado.

Em 2007, a Apple decidiu redesenhar a tela do Iphone, substituindo a anterior por uma de vidro, poucas semanas antes do lançamento, o que exigira uma revisão da linha de montagem. Os fornecedores e montadores norte-americanos da empresa alegaram que não havia tempo hábil para tanto, porém os fabricantes chineses, que mantinham dormitórios e sistemas de turnos de trabalho de doze horas, assumiram o contrato. Foram convocados aproximadamente 8000 trabalhadores dos alojamentos. Os trabalhadores receberam uma xícara de chá e um biscoito e, dentro de noventa e seis 
horas, a planta industrial passou a produzir mais de 10.000 Iphones por dia, com velocidade e flexibilidade de trabalho que nenhuma fábrica norte-americana lograria (DUHIG, 2012).

Dado o cenário de concentração midiática nas ações da Foxconn, os produtos mais conhecidos e prestigiados da Apple passaram a ser fabricados e montados pela Pegatron, que superou a concorrente no crescimento das receitas anuais e alta na bolsa de valores, mesmo que esta permuta tenha funcionado como uma nuvem de fumaça, com o objetivo em dissimular as práticas empresariais de barateamento de custos e não em prestigiar uma companhia que valorizasse o trabalho decente (Gráfico 2) (CHINA LABOR WATCH, 2015, p. 5):

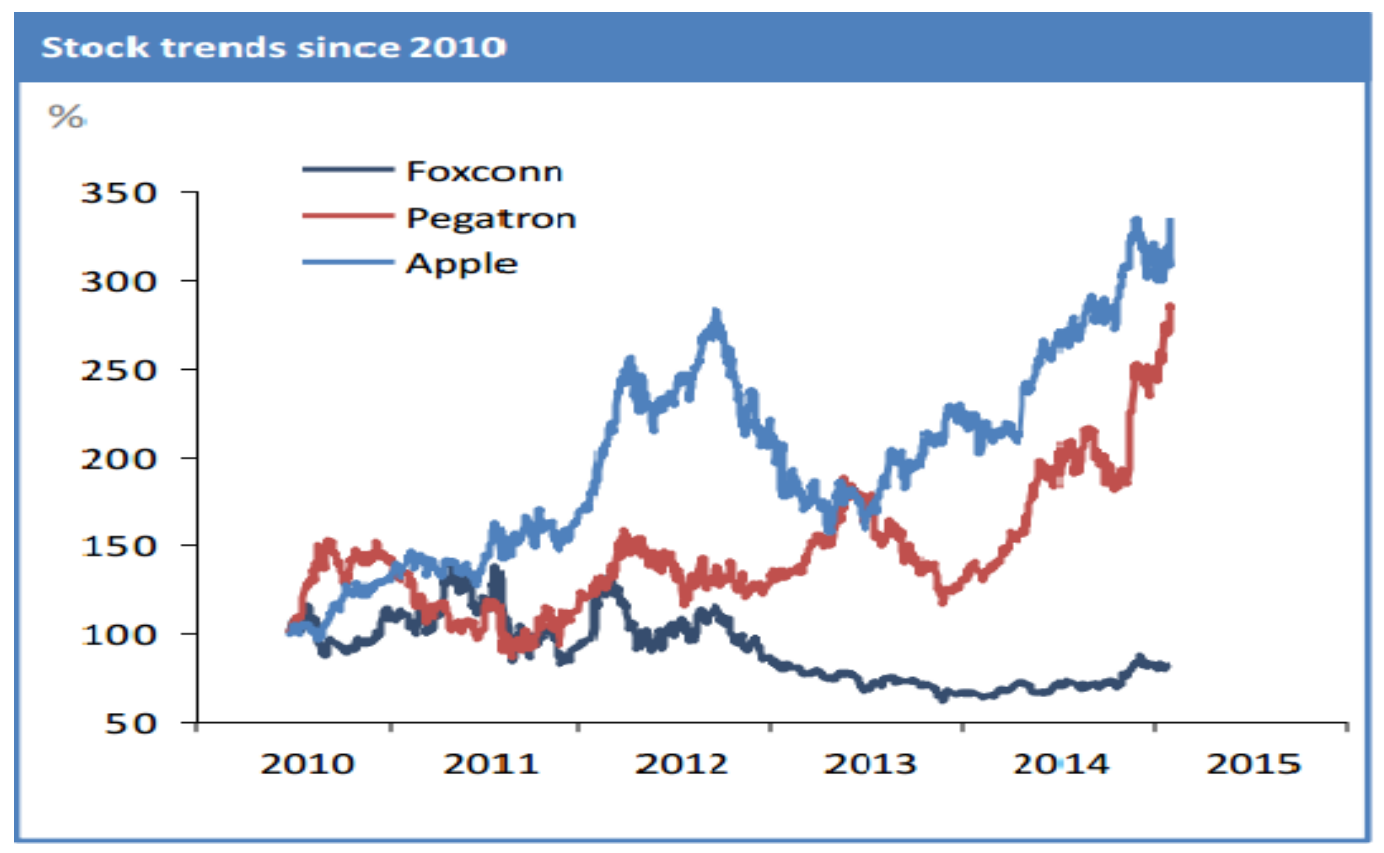

Gráfico 2 - Tendências de ações desde 2010

Enquanto as ações da Pegatron e da Apple caminham em escala ascendente, a Foxconn, desde 2011, tem sofrido desvalorização unitária. Além da queda de sua vantagem concorrencial pelo aumento dos custos trabalhistas, a exposição midiática das denúncias e da associação da marca a condições reprováveis de gestão de trabalho, afastando a Foxconn do conceito de responsabilidade social e governança corporativa, promoveu a fuga de investimentos para outros setores.

A Apple foi beneficiada pela sucessão dos fatos descritos. A marca estadunidense coleciona posições invejáveis no mercado de dispositivos móveis. A 
evolução dos lucros da Apple supera a soma de todas as suas maiores concorrentes, conforme o gráfico a seguir (Gráfico 3 - Valores em porcentagem dos lucros das operadoras de dispositivos móveis compartilhados pelos Fabricantes originais de equipamento) (CHINA LABOR WATCH, 2015, p. 25):

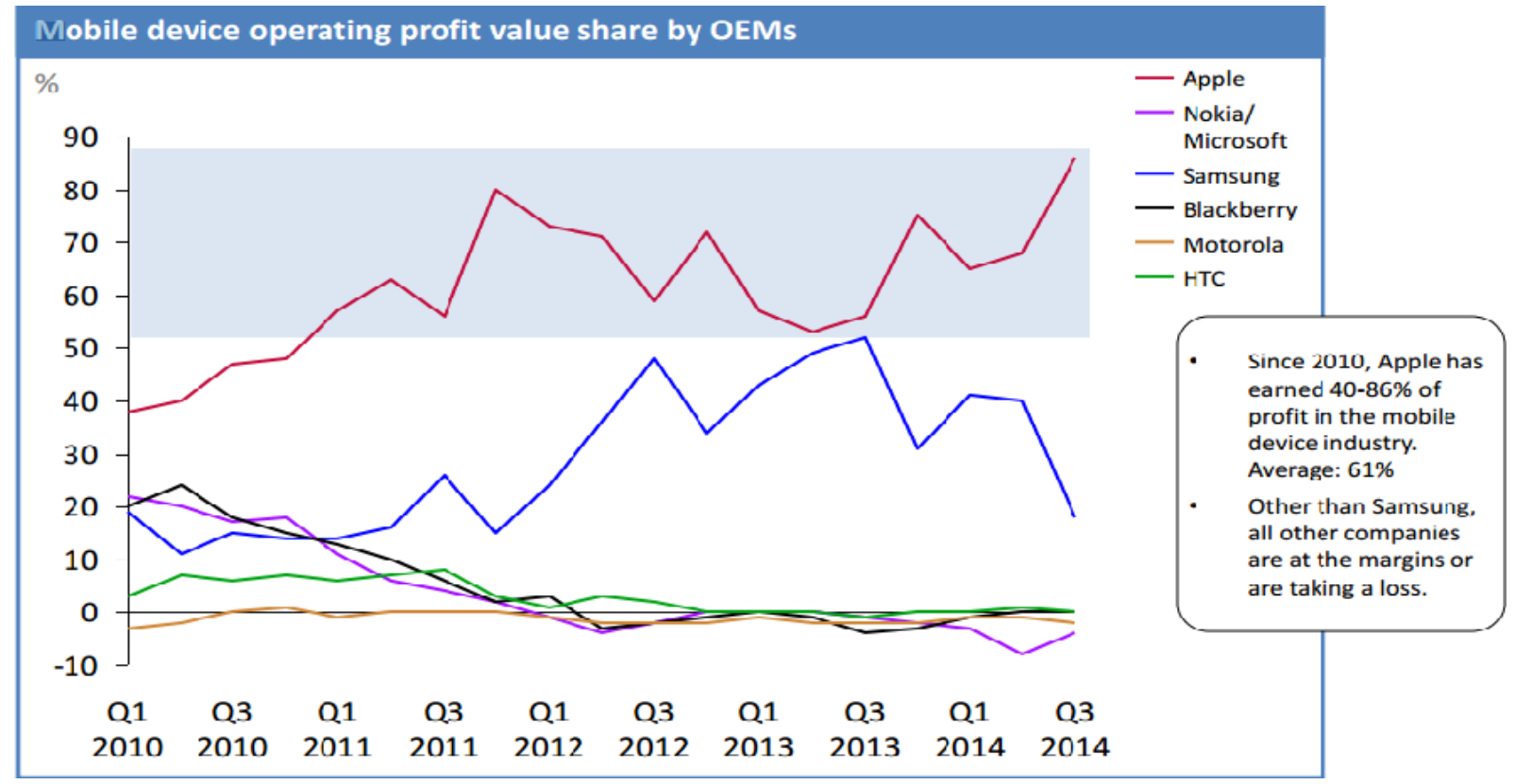

Gráfico 3 - Valores em porcentagem dos lucros das operadoras de dispositivos móveis compartilhados pelos Fabricantes originais de equipamento

Muito embora a afirmação de que a posição dominante tenha se dado unicamente por eficiência de custos trabalhistas seja de difícil e até improvável comprovação, os dados demonstram que há posição privilegiada no setor pela Apple e a análise integrada com os gráficos anteriores permite afirmar que há indícios de dominação de mercado facilitada pelo abuso de condições de trabalho mais competitivas, que resultam em abuso do poder econômico.

O conhecimento da realidade chinesa expõe os trabalhadores daquele país a um sacrifício concorrencial na medida em que são destinatários de escolhas meramente econômicas, reduzindo-os à mercancia, conduta que contraria os fundamentos básicos do direito internacional do trabalho.

Confrontada com as graves vinculações de sua marca a práticas imorais de trabalho humano, a Apple, desde 2005, tem divulgado relatórios anuais (Supplier Responsability Progress Reports) sobre auditorias nas empresas subsidiárias e parceiras quanto às condições de trabalho com a criação dos Códigos de Conduta dos 
Fornecedores, aos padrões de responsabilidade do fornecedor, ao monitoramento da gestão da força de trabalho e a respeito da responsabilidade ambiental. Em todos esses relatórios há o reconhecimento pela empresa de violações de direitos trabalhistas que variam entre contratação de trabalho infantil, a cobrança de taxas de recrutamento, 0 descuido com o descarte de produtos tóxicos nas fábricas, a adulteração de registros dos trabalhadores pelas empresas fornecedoras contratadas, dívidas por trabalho forçado, a ausência de licenciamento ambiental, o alto índice de doenças ocupacionais, o não pagamento de salário mínimo aos empregados e as jornadas exaustivas.

Em 2014, a Apple, realizou 633 auditorias nos fornecedores, em 19 países, que cobriram mais de 1.6 milhões de trabalhadores, cujos resultados no reembolso de US\$ 3.96 milhões decorrentes de taxas excessivas cobradas por agenciadores de trabalhadores estrangeiros, US\$ 900.000 a título de horas extras não pagas, encaminhamento de trabalhadores mirins para escolas com mensalidade integral e salário (APPLE, 2015, p. 5-6). Quanto à promoção da saúde dos empregados, a meta de limitação de jornada semanal para os trabalhadores das fábricas parceiras é de 60 horas semanais, dado que as jornadas extenuantes são objeto de denúncias recorrentes na cadeia de fornecedores e a total eliminação do trabalho infantil.

As auditorias trabalhistas, sociais e ambientais são realizadas por experts em cada matéria, lideradas por um auditor da Apple e apoiadas por auxiliares locais. Contemplam vinte áreas de abordagem, com destaque para trabalho e direitos humanos, saúde e segurança, meio ambiente, sistemas de gerenciamento e ética. O protocolo de fiscalização segue cinco fases: preparação, auditoria local, ações corretivas, monitoramento e verificação de correções. Engloba uma série de ações que envolvem visualização in loco das condições de trabalho, entrevistas com trabalhadores, confecção de planos de correção junto aos fornecedores, aplicação de sanções a estes últimos, que podem culminar até no encerramento dos contratos com a companhia (APPLE, 2015, p. 8-9).

As denúncias veiculadas na internet, nos canais de televisão e demais meios midiáticos despertaram em todo o globo um engajamento de organizações não governamentais, ativistas de direitos humanos, mas, sobretudo, a informação dos 
consumidores que passaram a exigir explicações da companhia e melhorias no tratamento de questões socioambientais na produção dos dispositivos eletrônicos adquiridos. O resultado foi o pressionamento das autoridades chinesas a dedicarem maior atenção na investigação e fiscalização das graves violações de direitos sociais trabalhistas.

O ponto de partida de um epicentro de mudanças, em especial nos níveis salarias pagos pela Foxconn, note-se, não se originou de uma postura de proatividade de autoridades públicas ou de uma conduta de eficiência qualitativa de produção industrial. Foi a preocupação com a opinião pública e, principalmente, com os consumidores que motivou a mudança de rota em temas relacionados ao mundo do trabalho, que criou uma necessidade de correção de imagem pública com as condições trabalhistas funcionando como lastro de mudança.

A estratégia da Apple, entretanto, tratou de desviar o foco das denúncias. Em 2012, a empresa contratou a consultoria da Fair Labor Association na tentativa de melhorar a imagem pública e desviar a atenção da marca Apple e as práticas trabalhistas reprováveis para a Foxconn, centro das denúncias de 2010. Nesse mesmo período, a Pegatron continuava a operar para a Apple em condições degradantes, mas sem receber os holofotes apontados para a Foxconn, o que ocasionou a melhoria de vida dos trabalhadores apenas da Foxconn, que sacrificou sua fatia de mercado, mantendo o benefício de custos para a Apple, destinatária da maior parte da produção nas fábricas da Pegatron.

A estratégia de marketing foi revelada no final de 2014 quando o canal inglês BBC News exibiu o documentário Apple's Broken Promises sobre as condições de trabalho numa fábrica da Pegatron, em Xangai. Um repórter infiltrou-se na linha de produção e demonstrou que todas as promessas realizadas de melhoria de condições de vida postas nos relatórios anuais de auditoria e divulgadas na imprensa quanto aos fornecedores não haviam sido cumpridas. Os cinquenta e oito minutos do documentário expõem graves violações de direitos básicos, tais como a retenção de documentos de identificação no processo de recrutamento, o que não permitiria a desistência da vaga de emprego, pressões psicológicas, jornadas exaustivas que atingiam até dezesseis horas diárias por 
dezoito dias consecutivos sem descanso semanal e registros de trabalho infantil em minas de estanho na Indonésia (APPLE'S BROKEN PROMISES, 2014).

\section{CONCLUSÃO}

A modernidade, o avanço tecnológico, a difusão da informação e a mobilidade trabalhista e produtiva trouxeram para o interior das relações humanas mudanças substancialmente consideráveis, com capacidade mutacional até agora não experimentada nestas proporções.

O caso Apple é emblemático, na demonstração da função concorrencial do direito do trabalho, vez que se refere a uma marca integrante da cultura consumerista infligida aos tempos hodiernos e à aquisição de aparelhos eletrônicos produzidos mediante a exploração humana e o absoluto desrespeito às regras fundamentais de tutela à integridade física, moral e econômica dos trabalhadores.

Os dados colacionados demonstram de modo hialino o empoderamento econômico da Apple, a posição dominante frente aos seus maiores concorrentes por meio do aumento arbitrário dos lucros potencializados por uma eficiência dissociada da noção mais elementar de ética e de responsabilidade social corporativa.

Trata-se de uma amostragem que denota apenas uma entre tantas outras companhias que produzem produtos e fornecem serviços que se tornaram praticamente constituintes das identidades consumeristas recentes. Neste campo de tantas contradições entre imagem, publicidade, consumo, trabalho e realidade, o desafio lançado ao direito positivo é o de mediador entre o acesso a uma concorrência salubre, que disponibilize, numa cadeia de trabalho decente, produtos de qualidade aos consumidores.

Mesmo que as demandas não sejam simples, as soluções acompanham a mesma lógica. Imprescindível o zelo aos direitos trabalhistas sob a perspectiva dos padrões internacionais estabelecidos pela Organização Internacional do Trabalho e como a ordem instituidora da OIT contribui na construção do conceito de Paraísos Normativos para uma possível relação de atuação normativa em cooperativa com a Organização Mundial do 
Comércio e demais órgãos encarregados de monitorar e regulamentar os aspectos econômicos do trade global.

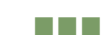

\section{REFERÊNCIAS}

APPLE. Supplier Responsability 2015 - Progress Report. Disponível em: < https://www.apple.com/anzsea/supplier-

responsibility/pdf/Apple_Progress_Report_2015.pdf>. Acesso em: 04 nov. 2015.

. Supplier responsability. Disponível em: <http://www.apple.com/supplierresponsibility/our-suppliers/>. Acesso em: 13 out. 2015.

APPLE'S Broken Promises. Direção: James Oliver e Matt Bardo. Produção: BBC Panorama. Londres: BBC, 2014. Documentário, 58'58'. Disponível em: < http://www.dailymotion.com/video/x2df9zb_bbc-panorama-apple-s-brokenpromises_tv>. Acesso em: 04 nov. 2015.

BAKER \& MCKENZIE INTERNATIONAL. China Employment Law Guide - 2013. Disponível em:

<http://www.bakermckenzie.com/files/Uploads/Documents/North\%20America/DoingBu sinessGuide/Dallas/br_china_employmentlawguide_13.pdf>. Acesso em: 10 out. 2015.

CHINA LABOR WATCH. Analyzing Labor Conditions of Pegatron and Foxconn: Apples's low cost reality. New York: CLW, 2015. Disponível em: <http://www.chinalaborwatch.org/upfile/2015_02_11/Analyzing\%20Labor\%20Condition s\%20of\%20Pegatron\%20and\%20Foxconn_vF.pdf>. Acesso em: 12 out. de 2015.

DUHIGG, Charles; BRADSHER, Keith. How the U.S. lost out on iPhone work. New York: The New York $2012 . \quad$ Times, Disponível em: <http://www.nytimes.com/2012/01/22/business/apple-america-and-a-squeezed-middleclass.html?_r=5\&ref=charlesduhigg\&pagewanted=all/>. Acesso em: 14 nov. 2015.

GOLD, Michael. Apple's inability to monitor standards lets Pegatron pay low wages, NGO says. Taipei: $2012 . \quad$ Deuters, em: <http://www.reuters.com/article/2015/02/12/us-apple-pegatron-labouridUSKBNOLG0P820150212>. Acesso em:12 out. 2015.

JACKSON, Nathan. Chinese Labor and Employment Law. Lowa: University of lowa Center for International Finance and Development, 2011.

KOPCZAK, Laura Rock. A Case Study of Apple Computer's Supplier Hubs: A Tale of Three Cities. DORNIER, Philippe-Pierre et al (org,). Global Operations and Logistics: Text and Cases. New Jersey: Wiley, 1998, p.186-196.

LASHINSKY, Adam. Nos bastidores da Apple: como a empresa mais admirada (e secreta) do mundo realmente funciona. São Paulo: Saraiva, 2012. 
MASIERO, Gilmar et al. Competitividade industrial chinesa: impacto econômico e realidade socioambiental. Curitiba: Juruá, 2012.

MINISTÉRIO DO DESENVOLVIMENTO, INDÚSTRIA E COMÉRCIO. Medidas em Vigor. Disponível

em:

<http://www.mdic.gov.br//sitio/interna/interna.php?area=5\&menu=4027>. Acesso em: 30 set. 2015.

SILVA, Iris Elena da Cunha Gomes da. Dumping Social e relações de trabalho na China. Dumping social e relações de trabalho na China. Revista Eletrônica do Ministério Público do Estado de Goiás, Goiás, n. 2, p. 43-54, jan./jun. 2012, p.47. Disponível em: [http://www.mp.go.gov.br/revista/pdfs_2/3-artigo7_dumping.pdf]. Acesso em: 05 out. 2015.

The Heritage Foundation. 2015 Index of Economic Freedom - Promoting Economic Opportunity and Prosperity. Disponível em: <http://www.heritage.org/index/pdf/2015/book/Highlights.pdf>. Acesso em: 05 out. 2015.

WORLD BANK. World Development Indicators. Washington D.C.: Disponível em: < http://data.worldbank.org/country/china\#cp_gep>. Acesso em: 05 out. 2015.

ZIMMERMAN, James. Labour Law: Trends and practices in China. Rule of Law in China:

Chinese Law and Business, London, FLJS, n. 6, 2007. Disponível em: <http://www.fljs.org/sites/www.fljs.org/files/publications/Zimmerman.pdf>. Aceso em: 03 ago. 2015.

LUCENA FILHO, Humberto Lima de. Dumping social transnacional e a República Popular da China. RBSD Revista Brasileira de Sociologia do Direito, v. 3, n. 2, p. 49 72, mai./ago. 2016.

Recebido em: 11/08/2016

Aprovado em: 23/08/2016 